\title{
The Childhood Growth of Twin Children
}

\author{
B. Luke', S. Leurgans ${ }^{2}$, L. Keith ${ }^{3,4}$, D. Keith ${ }^{4}$ \\ 'Department of Obstetrics and Gynecology, University of Michigan Medical School, Ann \\ Arbor, Michigan; 'Department of Preventive Medicine, Rush Medical College, Rush- \\ Presbyterian-St. Luke's Medical Center, Chicago, Illinois; ${ }^{3}$ Department of Obstetrics \\ and Gynecology, Northwestern University Medical School Chicago, Illinois; ${ }^{4}$ Center for \\ the Study of Multiple Birth, Chicago, Illinois
}

\begin{abstract}
The objective of this study was to assess the childhood growth of twin children in terms of the effects of intrauterine growth retardation (IUGR) and discordancy at birth on the incidence and severity of stunting and discordancy in current height and weight. The study was part of a cross-sectional field project conducted at the Annual Twins Days Festival in Twinsburg. Ohio, USA, during 1990, 1991, and 1993, and including all twin children between 2 and 12 years of age. Mothers of twins were interviewed regarding their children's birthweights and gestational age; the twin children were measured for their current heights and weights. The study population included 990 twin children, including 555 boys and 435 girls, of which there were 254 boy pairs and 194 girl pairs. Birthweight for gestational age and current weight and height were each converted into Z-scores and characterized as severe ( $Z$-score $<-2,0$ ), or moderate IUGR or stunting (Z-score $>-2.0$ and $<-1.2$ ). For the present study discordancy in birthweight, and current height and weight was calculated for like-gender twin pairs. Only twin children with severe IUGR at birth showed an increased risk of stunting in their current height or weight, and this risk was only for moderate, not severe, stunting. Boy twins with severe IUGR at birth were at increased risk of moderate stunting in their current weight (OR 2.67, 95\% CI 1.55, 4.58, $\mathrm{p}=0.002$ ), while girl twins with severe IUGR at birth were at increased risk of moderate stunting in their current height (OR 4,09, 95\% CI 1.49, 10.99, p = 0.003). Among like-gender twin pairs, there were no differences in mean or categories of birthweight or current weight discordancy, but boy twin pairs did show a significantly greater proportion of current weight discordancy compared to girl twin pairs $(\mathrm{p}=0.005)$. Overall, there was a significant tendency for differences in height and weight between like-gender twin pairs to disappear over time, with the effect being greater for boy twin pairs. We conclude from these findings that twin children tend to overcome growth retardation and discordancy present at birth, and although children who had severe IUGR or discordancy at birth were more likely to have some residual moderate stunting or discordancy in height or weight, they still tended to be within normal values for their gender and current age.
\end{abstract}

Key words: Twins, Childhood growth, Discordancy 


\section{INTRODUCTION}

During the past twenty years the twinning rate in the United States has increased dramatically, due to both a delay in childbearing and the increased use of assisted reproductive technologies [12]. According to the latest statistics, in 1993 there were 96445 twin births in the United States [17]. Compared to singletons twin infants are five times more likely to be born premature (less than 37 weeks' gestation), 9.5 times more likely to be very low birtweight (VLBW, less than $1500 \mathrm{~g}$ ), and 8.5 times more likely to be low birthweight (LBW, less than $2500 \mathrm{~g}$ ) [10]. Because of their overrepresentation among the premature and low birthweight cohorts of children in the United States, they are particularly suited as models to evaluate the effects of these adverse perinatal outcomes on childhood growth. In addition, because most twin pairs are discordant in birthweight to some degree (and many are extremely discordant), they are also ideal subjects for evaluating the effect of genetics versus environment on long-term growth. The results of prior studies are difficult to interpret because of small sample size or varying definitions of discordancy $[8,21,2,4,15,6,3]$.

As part of a multiyear field study of maternal nutrition and the childhood growth of twins at the annual Twins Days Festival in Twinsburg, Ohio, mothers of twins were interviewed regarding a variety of maternal nutrition issues, as well as the gestational age and birthweights of their twin children. The maternal nutrition component of the survey has been reported elsewhere [13]. The purpose of this portion of the study is to evaluate the childhood growth of twin children, both within twin pairs and compared to age and gender - specific singleton standards. This study was approved by the Human Investigation Committee at the Johns Hopkins University, the institution of the principal investigator at the initiation of the study.

\section{MATERIAL AND METHODS}

The Twins Days Festival is held annually during the first weekend of August in Twinsburg, Ohio, and includes children and adults of multiple gestations. The childhood growth component of this study was conducted during 1990,1991, and 1993, and included interviews with 495 mothers of twins and informations on their 990 twin children. In addition to nutrition questions, mothers were asked about expected and actual due dates, as well as the birthweights of their twin children. The gender of each twin was also documented. Although mothers were asked whether their liked-sexed twins were identical or fraternal, because the majority of responses were "unsure", these data were not used.

The height and weight of each child was measured after removal of the shoes, using the techniques of the National Health and Nutrition Examination Surveys [1]. Standing height was measured with the child wearing thin cotton socks, standing erectly with feet together, back and heels against the uprigth bar of the height scale, and head looking straight forward. Assistance and demonstration were provided when necessary, and the examiner exerted gentle upward pressure on the subject's mastoid process, as recommended by some. The equipment consisted of a level platform to which was attached a vertical bar with a steel measuri3ng rod. Attached perpendicularly to the vertical bar was 
a horizontal measuring rod, which was brought down snugly on the examinee's head. Examinees were weighed on a Health-O-Meter ProSeries Electronic Physician scale (model $592 \mathrm{KL}$ ), which provided a digital readout. The scales were factory-calibrated to within one-quarter pound accuracy, and recalibrated in the field with known weights before use. Because this study was conducted in August, clothing weight was considered constant and minimal.

Data were compared within each twin pair (as larger and smaller), and to gender and age specific singleton standards, based on birthweight data from the Centers for Disease Control and height and weight data from the second National Health and Nutrition Examination Survey [14]. Using birthweight data, percent discordancy and z-score were calculated. Percent discordancy was defined as the difference in the larger minus the smaller birghweight, divided by the larger birthweight, times 100 . The $\mathrm{z}$-score was defined as the observed value minus the expected value divided by the standard deviation of the expected value [7]. The z-score represents the distance of the observed value from the median of the age and gender specific reference values and is expressed in standard deviation (SD) units. For example, a z-score of -1.2 is $1.2 \mathrm{SD}$ below the median and is equivalent to about the 10th percentile, which corresponds to a moderate intrauterine growth retardation (IUGR) or stunting; a z-score of -2.0 represents a measurement 2 SD below the median, equivalent to about the 2 nd percentile and indicating a severe IUGR or stunting. Using current height and weight data, $z$-scores were also calculated for each twin child, as well as percent discordancy in current height and weight between like-gender twin pairs. Birthweight $\mathrm{z}$-scores and current weight and height $\mathrm{z}$-scores were forumlated as continuous variables and as categorical variables of moderate $(>2.0$ and $-1.2)$ and severe $(\leq-2.0)$ IUGR or stunting. Percent discordancy in birthweight was formulated as a continuous variable and as categorical variables of slight $(<10 \%)$, mild $(\geq 10,<15 \%)$, small $(\geq 15,<20 \%)$, moderate $(\geq 20,<25 \%)$, or severe $(\geq 25 \%)$. Percent discordancy in current weight was formulated as a continuous variable and as categorical variables of slight $(<10 \%)$, mild $(\geq 10,<15 \%)$, or small $(\geq 15,<20 \%)$. Percent discordancy in current height was formulated as a continuous variable and as categorical variables of minimal $(<5 \%)$ or slight $(\geq 5,<10 \%)$. The twin pairs were grouped according to gender as being both girls, both boys, and mixed gender pairs. The study population was limited to children who were at lest two years old and were less than 13 years old. The final study population included 990 twin children, including 555 boys and 435 girls, and 254 boy pairs ( 508 boys) and 194 girl pairs (388).

\section{Statistical Analysis}

First, the characteristics of boy twin pairs and girl twin pairs were compared using the Student's $t$ test for continuous variables and the chi-square test for categorical variables; with significance at $\mathrm{p}<0.05$, two-tailed (Table 1 ). Next, the odds ratios and $95 \%$ confidence intervals of moderate or severe stunting ( $\mathrm{z}$-scores $>-2.0,<-1.2$ and $\leq-2,0$, respectively) in current height and weight by moderate or severe IUGR in birghweight (z-scores of $>-2.0,<-1.2$ and $\leq-2.0$, respectively), were calculated using the Mantel-Haenszel chisquare test for trend, controlling for gender and current age (Table 2). Last, an overall chisquare test was calculated to evaluate the relationship between categories of birthweight discordancy and current height and weight discordancy, by gender (Table 3 ). 
Table 1 - Description of study population

\begin{tabular}{|c|c|c|c|}
\hline Variable & $\begin{array}{c}\text { Boy Twins } \\
\text { in Pairs }(n=508)\end{array}$ & $\begin{array}{c}\text { Girl Twins } \\
\text { in Pairs }(n=388)\end{array}$ & $p$ values \\
\hline $\begin{array}{l}\text { Gestation (mean weeks) } \\
\%<35 \text { weeks } \\
\% 35-35 \text { weeks } \\
\%>38 \text { weeks }\end{array}$ & $\begin{array}{c}36.6 \pm 2.9 \\
22 \% \\
48 \% \\
30 \%\end{array}$ & $\begin{array}{c}36.0 \pm 3.3 \\
27 \% \\
48 \% \\
25 \%\end{array}$ & NS ** \\
\hline $\begin{array}{l}\text { Current Age (mean years) } \\
\% \text { ages } 2-3 \\
\% \text { ages } 4-5 \\
\% \text { ages } 6-7 \\
\% \text { ages } 8-9 \\
\% \text { ages } 10-12\end{array}$ & $\begin{array}{c}6.7 \pm 3.1 \\
15 \% \\
22 \% \\
19 \% \\
16 \% \\
28 \%\end{array}$ & $\begin{array}{c}5.7 \pm 3.0 \\
21 \% \\
30 \% \\
19 \% \\
10 \% \\
20 \%\end{array}$ & $<0.0001$ \\
\hline $\begin{array}{l}\text { Birthweight (mean grams) } \\
\text { Z-score (mean } \\
\% \text { Moderate IUGR } * * * \\
\text { (Z-scores } \geq-2.0,<-1.2) \\
\% \text { Severe IUGR (Z-scores }<-2.0 \text { ) }\end{array}$ & $\begin{array}{c}2446 \pm 561 \\
-1.19 \pm 1.05 \\
29 \% \\
21 \%\end{array}$ & $\begin{array}{c}2485 \pm 623 \\
-0.56 \pm 1.07 \\
14 \% \\
7 \%\end{array}$ & $\begin{aligned} & \text { NS } \\
< & 0.0001 \\
< & 0.001 \\
< & 0.001\end{aligned}$ \\
\hline $\begin{array}{l}\text { Current Weight (mean pounds) } \\
\text { Z-score (mean) } \\
\% \text { Moderate Stunting } \\
(Z \text {-scores } \geq-2.0,<-1.2) \\
\% \text { Severe Stunting (Z-scores }<-2.0 \text { ) }\end{array}$ & $\begin{array}{c}49.8 \pm 22.3 \\
-0.55 \pm 1.00 \\
16 \% \\
6 \%\end{array}$ & $\begin{array}{c}45.5 \pm 20.5 \\
-0.21 \pm 1.11 \\
11 \% \\
1 \%\end{array}$ & $\begin{array}{c}0.003 \\
<0.0001 \\
\\
0.03 \\
<0.0001\end{array}$ \\
\hline $\begin{array}{l}\text { Current Height (mean inches) } \\
\text { Z-score (mean) } \\
\text { \% Moderate Stunting } \\
\text { (Z-scores } \geq-2.0,<-1.2 \\
\% \text { Severe Stunting (Z-scores }<-2.0 \text { ) }\end{array}$ & $\begin{array}{c}45.6 \pm 8.4 \\
-0.60 \pm 1.40 \\
17 \% \\
9 \%\end{array}$ & $\begin{array}{c}43.3 \pm 8.0 \\
-0.46 \pm 1.40 \\
10 \% \\
11 \%\end{array}$ & $\begin{array}{l}<0.0001 \\
\text { NS } \\
0.001 \\
\text { NS }\end{array}$ \\
\hline $\begin{array}{l}\text { Discordancy } \\
\text { Birthweight }(\text { mean } \%) \\
\% \text { Slight }(<10 \%) \\
\% \text { Mild }(\geq 10,<15 \%) \\
\% \text { Small }(\geq 15,<20 \%) \\
\% \text { Moderate }(\geq 20,<25 \%) \\
\% \text { Severe }(\geq 25 \%)\end{array}$ & $\begin{array}{l}9 \% \\
59 \% \\
20 \% \\
9 \% \\
9 \% \\
3 \%\end{array}$ & $\begin{array}{c}9 \% \\
59 \% \\
19 \% \\
10 \% \\
9 \% \\
3 \%\end{array}$ & NS \\
\hline $\begin{array}{l}\text { Discordancy } \\
\text { Current Weight (mean \%) } \\
\% \text { Slight }(<10 \%) \\
\% \text { Mild }(\geq 10,<15 \%) \\
\% \text { Small }(\geq 15,<20 \%)\end{array}$ & $\begin{array}{l}3 \% \\
84 \% \\
11 \% \\
5 \%\end{array}$ & $\begin{array}{l}2 \% \\
91 \% \\
6 \% \\
3 \%\end{array}$ & 0.005 \\
\hline $\begin{array}{l}\text { Discordancy } \\
\text { Current Height (mean \%) } \\
\% \text { Minimal }(<5 \%) \\
\% \text { Slight }(\geq 5,<10 \%)\end{array}$ & $\begin{array}{c}1 \% \\
96 \% \\
4 \%\end{array}$ & $\begin{array}{c}1 \% \\
95 \% \\
5 \%\end{array}$ & NS \\
\hline
\end{tabular}

* calculations based on number of pregnancies.

** NS is not statistically significant, $\mathrm{p}>0.05$, two-tailed.

*** IUGR is intrauterine growht retardation. 


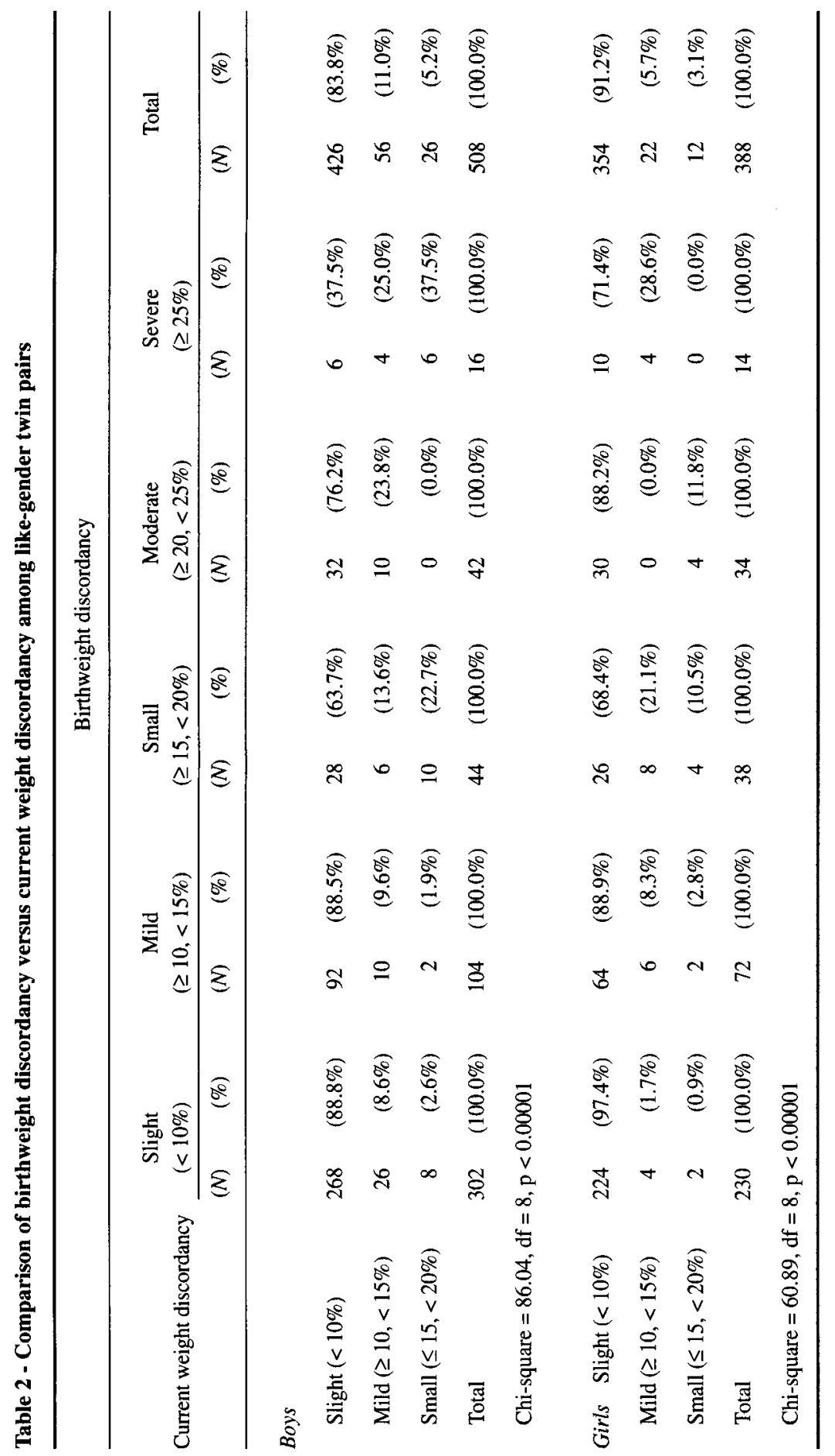




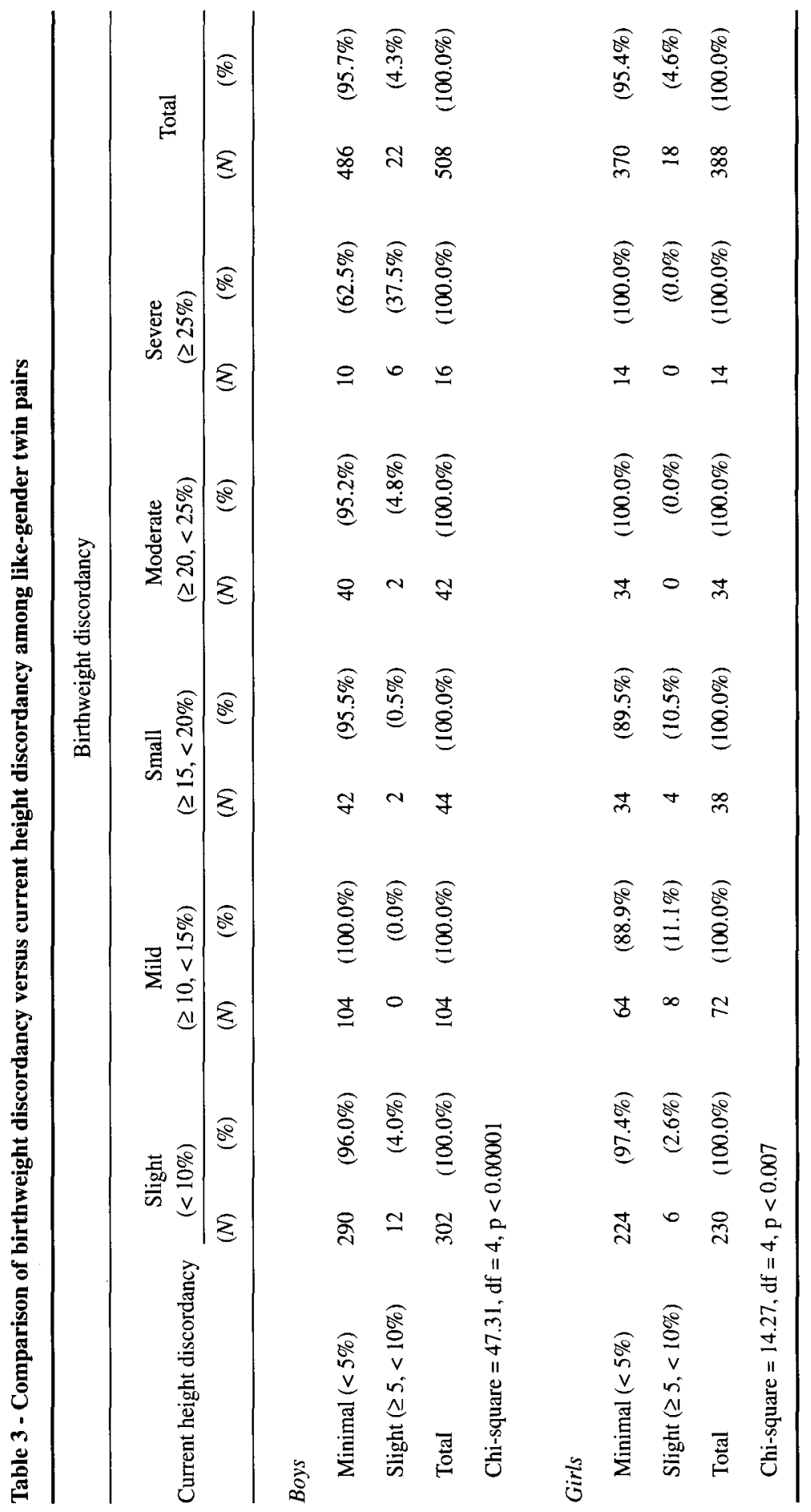




\section{RESULTS}

The characteristics of the study population are given in Table 1 for like-gender pairs. Boy twin pairs averaged about 0.6 week longer length of gestation $(p=0.01)$, but did not differ in their distribution within gestational categories compared to girl twin pairs. The current age of boy twin pairs averaged about one year older than girl twins $(p<0.001$ ), and boy twins had a greater percentage distribution of older ages $(p=0.001)$. Although boy and girl twin pairs did not differ significantly in their mean birthweights, they did differ significantly in their mean birthweight $\mathrm{z}$-scores and percentage of moderate and severe growth retardation at birth $(\mathrm{p}<0.001)$. As would be expected, boy twins were currently both heavier and taller than girl twins ( $\mathrm{p}=0.003$ and $<0.0001$, respectively), but they showed a greater incidence of moderate $(16 \%$ vs $11 \%, \mathrm{p}=0.03)$ and severe $(6 \%$ vs $1 \%, \mathrm{p}<0.0001)$ stunting in current weight compared to the girl twins. The difference and magnitude in stunting in current height was less dramatic, although boy twins still had significantly more moderate stunting compared to girl twins (17\% vs $10 \%$, $p=0.001$ ).

The percentage of moderate and severe birthweight discordancy was similar among boy versus girl twin pairs, but the former had a greater proportion of current weight discordancy $(p=0.005$ ). Boy twin pairs and girl twin pairs did not differ in current height discordancy, nor in their incidences of moderate or severe current height discordancy.

Only twin children with severe IUGR at birth showed an increased risk of stunting in their current height or weight, and this risk was only for moderate, not severe, stunting. Boy twins with severe IUGR at birth were at increased risk of moderate stunting in their current weight (OR 2.67, 95\% CI 1.55, 4.58, p = 0.0002), while girl twins with severe IUGR at birth were at increased risk of moderate stunting in their current height (OR $4.09,95 \%$ CI 1.49, 10.99, $\mathrm{p}=0.003$ ).

For both types of like-gender twin pairs, there was a strong tendency for birthweight discordancy to disappear over time (Tables 2 and 3).

\section{DISCUSSION}

In this study it was shown that twin children generally recover from their initial birth deficits (as weight for gestational age or birthweight discordancy), and although those with severe IUGR or discordancy at birth may remain somewhat smaller than their sibling counterparts during childhood, both twins were very likely to be within normal singleton standards.

\section{Discordancy}

Discordancy can occur from a variety of factors, including site of the placenta(s), implantation, crowding or position in the third trimester, or placental abnormalities such as anastomoses or a single umbilical artery. Discordancy is associated with significantly increased risks of fetal, perinatal, and neonatal mortality for the smaller twin $[8,6]$. Currently there is no consensus regarding a definition of birthweight discor- 
dancy, with older literature suggesting as much as $25 \%$ [2], while newer studies suggest as little as $15 \%[4,15,3]$. Differences greater than $15 \%$ are more likely to be associated with IUGR [15].

Some follow-up studies of twins with birtweight discordancies of $25 \%$ or more reported no differences in height, weight, or head circumference at age 9.5 , nor any differences in gross motor performance or mean school grades. Differences were reported in fine motor performance, balance, coordination, and visual-motor perception favoring the larger birthweight twin [21]. Other studies of twins with birthweight discordancies of $25 \%$ or more reported that at one year of age the lighter twin tended to remain smaller, but to be within normal limits [16].

\section{Growth Retardation}

Twin infants are much more likely than singletons to be born premature, as well as to experience intrauterine growth retardation. For example, about $10 \%$ of singletons are born prematurely, before 37 weeks' gestation, compared to nearly $50 \%$ of twins [12]. The intrauterine growth of twins and singletons begins to diverge at about 30 weeks' gestation, with significant differences at 35 weeks and later [9]. Williams et al concluded that the peak growth rate in weight was about $250 \mathrm{~g} /$ week at 33 weeks for singletons, compared to $175 \mathrm{~g} /$ week at 31 weeks for twins [18]. According to data from the Louisville Twin Study, after 31 weeks' gestation the average twin birthweight falls progressively behind that of singletons, such that by 38 weeks the singleton tenth percentile is equivalent to the twin 50th percentile and the singleton 50th percentile is equivalent to the twin 90th percentile [20]. In the absence of growth retardation, twins do not experience any excess neonatal morbidity compared to singletons $[5,11]$.

In the United States, the largest study of the growth fo twin children conducted to date has been the Louisville Twin Study at the University of Louisville. Growth data are based on more than 1000 twins who have been recruited and measured since 1962. This study reported dramatic reductions in weight deficits of twins compared to singletons during the first postnatal year, with differences completely diminishing by age eight, even among children who had moderate or severe IUGR at birth [20].

Ronald Wilson, the past director of the Louisville Twin Study, summarized their findings as follows:

"There are recuperative capabilities and qualities of resilience even among risk infants that steadily compensate for the burden of prematurity. Such qualities bring into focus the fact that developmental processes are continuous and ongoing, and they possess intrinsic self-correcting tendencies... under supportive conditions, most at-risk infants will recoup from early trauma and progress toward a level commensurate with their targeted capabilities » [19].

The greatest limitation of our field study is the lack of reliable information on zygosity. In the United States zigosity of twin pairs is not routinely determined at birth, and therefore remains a limitation in studies of twins. We have grouped our twins by likegender pairs, presuming similar genetic dispositions, although it is well-known that same gender siblings can differ greatly in their physical characteristics. Despite this limitation, 
this study adds to the body of scientific literature supporting the concept that, given a conducive environment, children can overcome prenatal and early postnatal deficits to realize their genetic potentials.

\section{CONCLUSIONS}

We conclude that the initial birth deficits so common among twin children decrease in incidence and severity over time, and even when differences between twin pairs remain, both twins tend to be within normal limits for their age and gender.

Acknowledgement: The authors would like to acknowledge support from the Center for the Study of Multiple Birth and Health-O-Meter, Inc. of Bridgeview, Illinois.

\section{REFERENCES}

1. Abraham S (1979): Weight by height and age for adults 18-74 years, United States, 1971-74. Vital and Health Statistics: Series 11, Data from the National Health Survey; No. 208. DHEW Pub. No. (PHS) 79-1656. Hyattsville, Md.

2. Babson SG, Phillips DS (1973): Growth and development of twins dissimilar in size at birth. New Engl J Med 289: 937-940.

3. Blickstein I, Shoam-Schwartz Z, Lancet M, Borenstein R (1987): Characterization of the growth-discordant twin. Obstet Gynecol 70: 11-15.

4. Blickstein I, Shoman-Schwartz Z, Lancet M (1988): Growth discordancy in appropriate for gestational age, term twins. Obstet Gynecol 72: 585-4.

5. Bronsteen R, Goyert G, Bottoms S (1989): Classification of twins and neonatal morbidity. Obstet Gynecol 74: 98-101.

6. Crane JP, Tomich PG, Kopta M (1980): Ultrasonic growth patterns in normal and discordant twins. Obstet Gynecol 55: 678-683.

7. Dibley MJ, Staehling N, Nieburg P; Trowbridge FL (1987): Interpretation of Z-score anthropometric indicators derived from the international growth reference. Am J Clin Nutr 46: 749-62.

8. Erkkola R, Ala-Mello S, Piiroinen O, Kero P, Sillanpaa M (1985): Growth discordancy in twin pregnancies: a risk factor not detected by measurements of biparietal diameter. Obstet Gynecol 66: 203-6.

9. Luke B, Witter FR, Abbey H, Feng TI, Namnoun AB, Johnson TRB (1991): Gestational agespecific birthweights of twins versus singletons. Acta Genet Med Gemellol 40: 69-76.

10. Luke B, Keith LG (1992): The contribution of singletons, twins, and triplets to low birthweight, infant mortality, and handicap in the United States. J Reprod Med 37: 661-6.

11. Luke B, Minogue J, Witter Fr (1993): The role of fetal growth restriction and gestational age on lenght of hospital stay in twin infants. Obstet Gynecol 81: 49-53.

12. Luke B (1994): The changing pattern of multiple births in the United States: maternal and infant characteristics, 1973 and 1990. Obstet Gynecol 84: 101-6.

13. Luke B, Leurgans S (1996): Maternal weight gains in ideal twin pregnancies. J Am Dietet Assoc; 96: 178-181.

14. Najjar MF and Rowland M (1987): Anthropometric reference data and prevalence of overweight, United States, 1976-80. Vital and Health Statistics. Series 11, No. 238. DHHS Pub. No. (PHS) 87-1688. Publich Health Service. Washington, DC. 
15. O'Brien WF, Knuppel RA, Scerbo JC, Rattan PK (1986): Birth weight in twins: an analysis of discordancy and growth retardation. Obstet Gynecol 67: 483-6.

16. Philip AGS (1981): Term twins with discordant birth weights: observations at birth and one year. Acta Genet Med Gemellol 30: 203-212.

17. Ventura SJ, Martin JA, Taffel SM, Mathews TJ, Clarke SC (1995): Advance report of final natality statistics, 1993. Monthly Vital Statistics Report, Vol. 44, No. 3, Suppl. Hyattsville, MD: National Center for Health Statistics.

18. Williams RL, Creasy RK, Cumingham GC, Hawes WE, Norris FD, Tashiro M (1982): Fetal growth and perinatal viability in California. Obstet Gynecol 89: 624-32.

19. Wilson RS (1985): Risk and resilience in early mental development. Dev Psychol 21: 795-805.

20. Wilson RS (1986): Growth and development of human twins. In Falkner F and Tanner JM (eds). Human Growth, A Comprehensive Treatise, second edition. New York: Plenum Press, pp. 197-211.

21. Ylitalo V, Kero P, Erkkola R (1988): Neurological outcome of twins dissimilar in size at birth. Early Human Dev 17: 245-255.

Correspondent: Dr. Barbara Luke, Dept. Obstetrics and Gynecology, University of Michigan Medical School, 1500 East Medical Center Drive, Ann Arbor, Michigan 48109-0264, USA. 